\title{
A DFT Study of Interaction of Carbon Monoxide with Carbonaceous Materials
}

\author{
Juan F. Espinal, ${ }^{\dagger}$ Alejandro Montoya, ${ }^{\dagger}$ Fanor Mondragón, ${ }^{* \dagger}{ }^{\dagger}$ and Thanh N. Truong*, ${ }^{*}$ \\ Institute of Chemistry, University of Antioquia, Medellin, Colombia A.A. 1226, and Henry Eyring Center for \\ Theoretical Chemistry, Department of Chemistry, University of Utah, 315 South 1400 East, Room 2020, \\ Salt Lake City, Utah 84112
}

Received: June 30, 2003; In Final Form: October 7, 2003

\begin{abstract}
Reaction of $\mathrm{CO}$ with carbonaceous surfaces was investigated using B3LYP density functional theory level (DFT) with the 6-31G(d) basis set. It was found that $\mathrm{CO}$ can be adsorbed exothermically on the active sites of zigzag, armchair, and tip carbonaceous models to yield stable intermediates such as cyclic ether, carbonyl, lactone, ketone, carbonate, and semiquinone functionalities. The above reactions are important in carbon gasification processes as well as in carbon single-wall nanotubes formation from $\mathrm{CO}$ disproportionation reaction. In the case of gasification, adsorption of $\mathrm{CO}$ blocks the active sites of the carbonaceous material and thus can reduce the efficiency of the process. Furthermore, it was found that when $\mathrm{CO}$ is adsorbed in a carbonyl type structure $(\mathrm{C}=\mathrm{C}=\mathrm{O})$, there is a reversible interconversion process by ring closure with a neighbor active site to produce a cyclic ether (furan type), a process that requires an additional neighboring active site. Consequently, the available number of active sites for gasification reaction is decreased and therefore the gasification reaction is inhibited. In addition, $\mathrm{CO}$ adsorption on oxidized surfaces can favor $\mathrm{CO}_{2}$ desorption. Such desorption can be either taking off an oxygen atom that potentially was going to be desorbed as $\mathrm{CO}$ or depositing a carbon atom on the surface due to the disproportionation reaction $2 \mathrm{CO}=\mathrm{C}+\mathrm{CO}_{2}$. Both effects can inhibit or retard the gasification process. The results from the disproportionation reaction can also provide an insight into the mechanism for carbon single-wall nanotubes growth using $\mathrm{CO}$ as precursor.
\end{abstract}

\section{Introduction}

Adsorption of $\mathrm{CO}$ on carbonaceous surfaces is an important process in the gasification of carbon materials such as char, coke, soot, as well as in the growth of carbon single-wall nanotubes (SWNTs). Gasification is a process that takes place when carbon reacts with an oxidant agent in order to yield gaseous products that can be used as fuel or synthesis gas and thus it is a clean and efficient alternative to the use of coal instead of combustion. The gasification process involves chemisorption of oxygen from the oxidant agents, such as $\mathrm{CO}_{2}, \mathrm{H}_{2} \mathrm{O}$ and/or $\mathrm{O}_{2}$, on the carbonaceous surface and then desorption of carbon oxides, mainly CO, by heating. ${ }^{1}$ Since $\mathrm{CO}$ is one of the main products, its interaction with carbonaceous materials and surface oxygen complexes has been known to have an inhibition effect on the efficiency of the gasification process. ${ }^{2-5}$ Despite several experimental studies that have focused on such interaction, ${ }^{6-8}$ molecular description of its role in inhibition of the gasification process is not well understood.

Although it has been proposed that $\mathrm{CO}$ reacts with surface oxygen complexes to form carbon dioxide ${ }^{9}$ and that $\mathrm{CO}_{2}$ desorption peaks during temperature-programmed desorption (TPD) are due to $\mathrm{CO}$ readsorption on the carbon surface, ${ }^{10}$ formation of stable carbon-oxygen complexes (due to $\mathrm{CO}$ adsorption) is not completely accepted because of the low sticking coefficient on graphite ${ }^{11}$ and the low CO concentration adsorbed on oxidized carbonaceous surfaces. ${ }^{8,12}$ There have been a few studies of $\mathrm{CO}$ adsorption on carbonaceous materials such as fullerenes, nanotubes, graphite, and diamond, and it was

* Corresponding authors. E-mail: fmondra@quimbaya.udea.edu.co; truong@chemistry.utah.edu.

$\dagger$ University of Antioquia.

$\doteqdot$ University of Utah. proposed that $\mathrm{CO}$ is weakly physisorbed on these materials. ${ }^{11,13-16}$ Grand Canonical Monte Carlo (GCMC) simulations have shown that carbon monoxide adsorption inside and outside singlewalled carbon nanotubes depends on pressure, temperature, and sorbent structure, so, under the proper conditions, it is a useful way to separate gas mixtures such as hydrogen and carbon monoxide because the interaction between $\mathrm{CO}$ and the tube wall is stronger than that of $\mathrm{H}_{2} \cdot{ }^{15} \mathrm{In}$ an experimental study of $\mathrm{CO}$ adsorption on graphite, it was assumed that almost all the observed adsorption occurs on the edge atoms and that almost none occurs on the basal plane, because the bonds that can be formed at the edge atoms are high-energy covalent bonds while only weak van der Waals forces are present at the basal planes. ${ }^{11}$ Semiempirical direct dynamics simulations have been used to investigate the potential role of $\mathrm{CO}$ in the gas-phase growth of SWNTs, assuming that the growth proceeds through the open edge of the nanotube instead of a root growth. It was found that $\mathrm{CO}$ can be adsorbed and contributes to the intermediate and latter stages of carbon nanotube growth, ${ }^{16}$ as has been observed experimentally. ${ }^{17-22}$ Theoretical studies on adsorption of $\mathrm{CO}$ on carbonaceous materials relevant in the coal gasification process at the molecular level so far has been very limited. Such studies would help to give a better understanding of its inhibition effect and thus to improve the efficiency of the process.

Previously we have successfully carried out a combined theoretical and experimental study on adsorption of $\mathrm{CO}_{2}$ on carbonaceous materials. ${ }^{23}$ Our theoretical results are in good agreement with the experimental data. Furthermore, several of the carbon-oxygen complexes that have been proposed in the literature were identified and characterized. In addition, we have studied the $\mathrm{CO}$ desorption from surface oxygen complexes, ${ }^{24}$ the reaction of NO with char-bound nitrogen during combus- 
a)

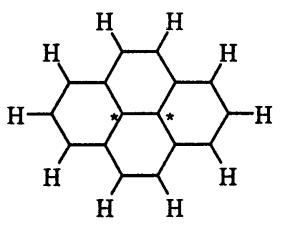

b)

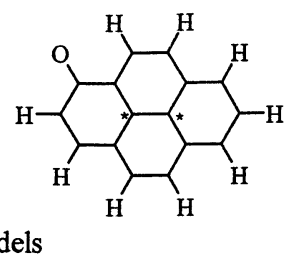

c)

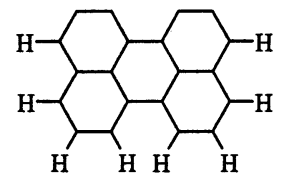

d)

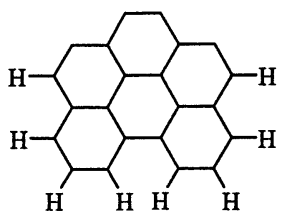

Armchair models

e)

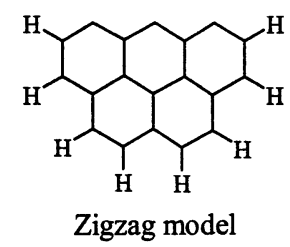

f)

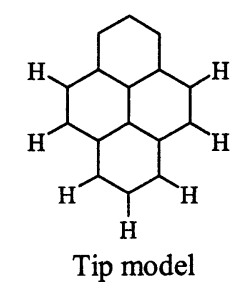

Figure 1. Some carbonaceous models used for studying the $\mathrm{CO}$ interaction. The carbon atoms marked with an asterisk are the ones used to simulate the adsorption on the basal plane.

tion, ${ }^{25}$ and several other studies that make molecular modeling a reliable method for studying the coal gasification reaction. ${ }^{26-29}$

Our goal, in this research, is to investigate the $\mathrm{CO}$ interaction with clean and oxidized carbonaceous models using density functional theories. In particular, our objectives are to study the adsorption of $\mathrm{CO}$ on unsaturated edges of carbonaceous materials, to characterize surface oxygen complexes, and to elucidate pathways for $\mathrm{CO}_{2}$ desorption and mechanisms which could be used to explain the $\mathrm{CO}$ inhibition behavior in coal gasification reactions as well as the growth of SWNTs.

\section{Computational Details}

Carbonaceous materials are considered macrostructures formed mainly by aromatic clusters. In the case of graphite, those aromatic clusters are parallel graphene layers. For char, it is known from solid-state ${ }^{13} \mathrm{C}$ NMR experiments that it has structures of randomly connected graphene clusters consisting of $12-25$ aromatic carbon atoms ( $3-7$ benzene rings).$^{30}$ Since an electron does not delocalize through single bonds efficiently, it is reasonable to assume that the reactivity of each graphene cluster is not affected by the remaining char structure. Carbon active sites are considered as unsaturated carbon atoms in the carbonaceous structure. In this study, carbonaceous models are represented by finite clusters of a single graphene layer where the edge atoms on the upper side of the models shown in Figures 1c, $1 \mathrm{~d}, 1 \mathrm{e}$, and 1f are unsaturated to simulate active sites while the other edge carbon atoms are terminated with hydrogen atoms. Since the $\mathrm{H} / \mathrm{C}$ ratio in char is known to be quite low as well as in graphite only the unsaturated edge is active, the model shown in Figures 1 are reasonable representation of the active site environment. Note that the $\pi$-bond network is implied in these figures. It has been shown previously that the use of $\mathrm{H}$ to terminate the boundaries of finite graphite models is a good choice. ${ }^{31}$ Several models have been proposed to simulate the different structures that can be found in a carbonaceous material (basal plane, armchair, zigzag, and tip models) as can be seen in Figure 1. It is important to note that, although graphite has

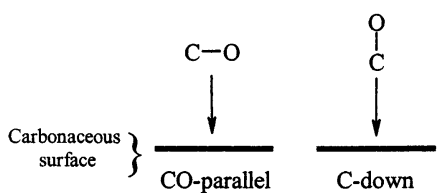

Figure 2. Geometric representation for CO interaction with carbonaceous models.

a much bigger structure where the graphene layers have different sizes and configurations, the carbonaceous models considered in this study are appropriated to represent the different active site environments that exist on carbonaceous materials ${ }^{23,24,27,28,32-34}$ and that it has been shown earlier that the interaction properties depend more strongly on the local structure of the active site than on the size of the graphene layer. ${ }^{23,24,31}$

To investigate the $\mathrm{CO}$ interaction with carbonaceous models we fully optimized each structure and the possible surface oxygen complexes that can be formed. All calculations (energies, optimizations, and frequencies) were made at B3LYP density functional theory level (DFT), using the 6-31G(d) basis set. In a previous study it was shown that spin contamination in unrestricted wave function at B3LYP level of theory is small for carbonaceous models. ${ }^{26}$ Each model was optimized in its electronic ground state. This was done by performing singlepoint energy calculations at the same level of theory for several electronic states using geometries that were optimized at the AM1 semiempircal method for a given species; the ground state is taken as the one with the lowest energy. Furthermore, frequency calculations were done in order to confirm their stability and to obtain IR spectra information of surface complexes. For all interaction energies reported below, the zero of energy is taken to be at infinite separation between $\mathrm{CO}$ and the carbon model. All calculations were done using the Gaussian 98 program. ${ }^{35}$

\section{Results and Discussion}

CO Adsorption on the Basal Plane. The interaction between the $\mathrm{CO}$ molecule and the basal plane of graphite was simulated using the models shown in Figures 1a and 1b. Both parallel and vertical adsorption modes as shown in Figure 2 were investigated. We found that the adsorption is very weak, as expected, since it is mainly from the dispersion interactions. It is known that DFT is not adequate to study the van der Waals interactions. Our previous study of $\mathrm{CO}_{2}$ adsorption on the graphite basal plane using both MP2 and DFT methods found that DFT underestimates the adsorption energies by about $2-3$ $\mathrm{kcal} / \mathrm{mol}$. With such results, we estimate the adsorption of $\mathrm{CO}$ on the basal plane to be of the order of $2-3 \mathrm{kcal} / \mathrm{mol}$. Since our interest here is to study the chemisorption of $\mathrm{CO}$ on carbonaceous materials, we need not pursue this issue further using more accurate level of theory.

CO Chemisorption on the Active Sites. Structures for the carbon-oxygen complexes formed upon adsorption of $\mathrm{CO}$ on selected carbonaceous models are presented in Figure 3. Normalmode analysis shows that these optimized complexes are local stable structures on the potential energy surface. However, such stability does not provide sufficient proof that these surface oxygen complexes exist under the gasification conditions, typical gasification temperatures are around $800-1000{ }^{\circ} \mathrm{C}$. It is found that $\mathrm{CO}$ interaction with the armchair models yields a larger number of surface complexes than with either zigzag or tip models, namely Figures $3 \mathrm{a}, 3 \mathrm{~b}, 3 \mathrm{c}$, and $3 \mathrm{~d}$ as compared to $3 \mathrm{e}$ and $3 \mathrm{f}$ for the zigzag and $3 \mathrm{~g}$ for the tip models. Formation of these complexes is energetically favorable with exothermicity 
a)

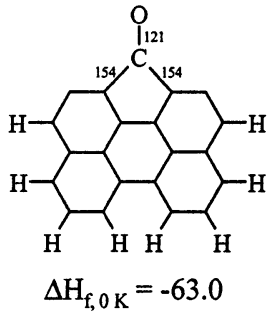

b)

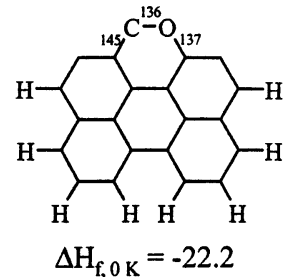

c)

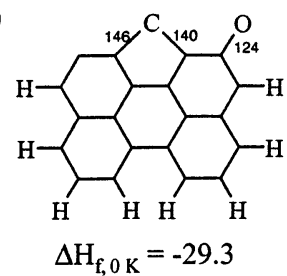

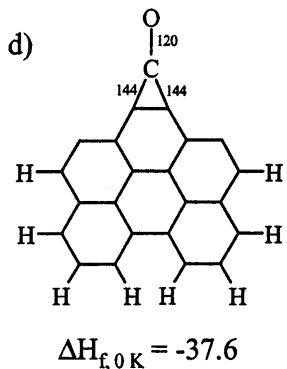

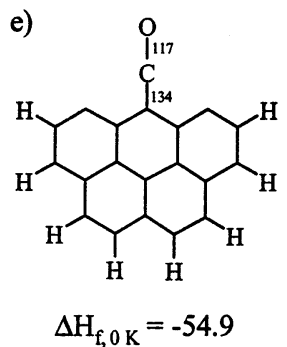

f)

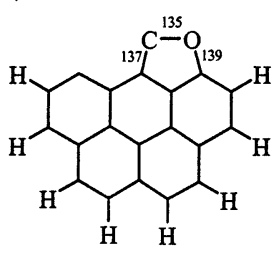

$\Delta \mathrm{H}_{\mathrm{f}, 0 \mathrm{~K}}=-55.2$

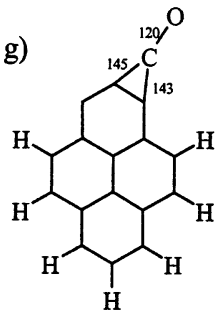

$\Delta \mathrm{H}_{\mathrm{f}, 0 \mathrm{~K}}=-33.3$

Figure 3. Structures of surface oxygen complexes formed after interaction of the CO molecule with carbonaceous models. Selected bond lengths are in $\mathrm{pm}$. Formation enthalpies are also shown for each complex in $\mathrm{kcal} / \mathrm{mol}$.

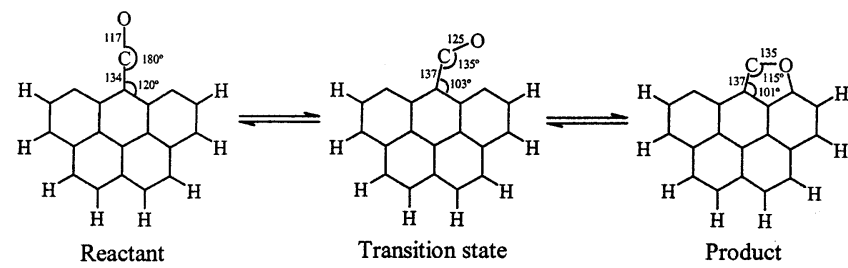

Figure 4. Reaction for transformation of carbonyl into ether model. Selected bond lengths are in pm and angles are in degrees.

larger than $22.2 \mathrm{kcal} / \mathrm{mol}$. Formation enthalpies are also shown in Figure 3. The data here suggest that the complex $3 \mathrm{c}$ could be generated by the dissociative chemisorption of $\mathrm{CO}$, splitting off the $\mathrm{C}-\mathrm{O}$ bond followed by a ring closure to form a fivemember ring and migration of an oxygen atom to a neighbor active carbon atom. The reaction that yields a cyclic ketone group on the armchair model (Figure 3a) has an interaction energy of $-63.0 \mathrm{kcal} / \mathrm{mol}$, and thus it would desorb at high temperatures during a TPD experiment.

Carbonyl and cyclic ether complexes formed on zigzag type structures have very similar adsorption energies (see Figure 3). Therefore, it is possible that the oxygen atom can migrate from the carbonyl group $>\mathrm{C}=\mathrm{C}=\mathrm{O}$ to a nearest neighboring active site to form a cyclic ether by a ring closure. Such a process has been previously proposed by Marchon et al. ${ }^{7}$ from the analysis of TPD results. We have investigated the energetics of such a transformation. Figure 4 shows the structures of the reactant, transition state, and product. Selected geometrical parameters are also included. The main geometrical change in the transition state structure with respect to the reactant is in the $\mathrm{C}-\mathrm{C}-\mathrm{O}$ angle that decreases from 180.0 to 134.8 degrees and in the marked $\mathrm{C}-\mathrm{C}-\mathrm{C}$ angle that decreases from 120.0 to 103.4 degrees (see Figure 4). These changes are a direct consequence of the oxygen atom moving to a neighboring active site in order to form the cyclic ether. A schematic energy profile for the transformation of the carbonyl into the five-member ring cyclic ether is shown in Figure 5. First of all, we found that the CO adsorption on a zigzag active site has a barrier of $19.4 \mathrm{kcal} /$ mol. Although the adsorption process to form the carbonyl surface oxygen complex is $54.9 \mathrm{kcal} / \mathrm{mol}$ exothermic. The transformation between the carbonyl and the five-member ring cyclic ether group has a barrier of $34.0 \mathrm{kcal} / \mathrm{mol}$ and is nearly thermally neutral. The energy profile suggests that inter-

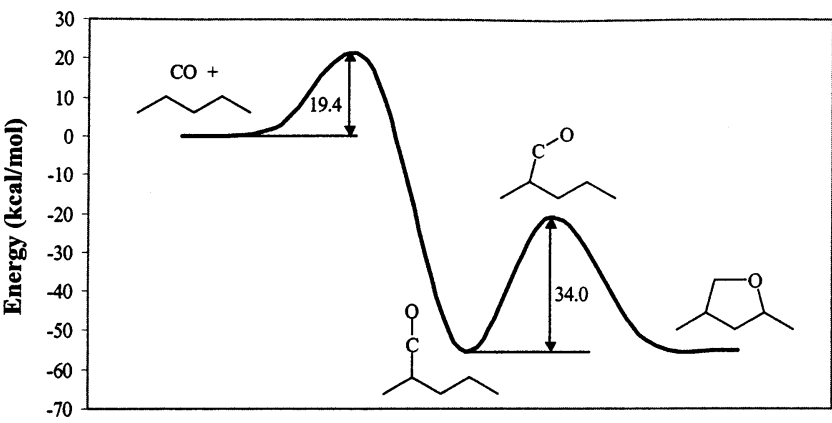

Figure 5. Energy plot for the transformation of carbonyl into ether model.

conversion between the carbonyl and five-member ring cyclic ether can occur spontaneously under the gasification conditions. It is important to note that such transformation requires two active carbon sites and therefore readsorption of $\mathrm{CO}$ would inhibit the yield of the gasification reaction due to the reduction of the active sites available to react with the oxidant gas. A similar argument can be made for the transformation between the ketone complex (Figure 3a) and the six-member ring cyclic ether group for $\mathrm{CO}$ adsorption on the armchair model. However, in this case the formation of the ketone group is much more favorable since it is more stable by about $41.8 \mathrm{kcal} / \mathrm{mol}$.

Adsorption of $\mathrm{CO}$ on the armchair and tip models can also form stable three-member ring carbonyl surface complexes such as Figure $3 \mathrm{~d}$ and $3 \mathrm{~g}$, respectively, with interaction energies in the range of -33.3 to $-37.6 \mathrm{kcal} / \mathrm{mol}$. In addition to all the above-mentioned complexes, we examined the possibility of forming four-member ring cyclic ether by adsorption of $\mathrm{CO}$ molecule on two adjacent active sites on armchair or tip configurations. However, we found that such processes are endothermic despite the fact that such complexes are locally stable on the potential surface as indicated by normal-mode analyses. Therefore it is very unlikely to observe these structures at the gasification conditions.

Surface Coverage Effect on CO Adsorption. As the gasification reaction proceeds, the number of surface oxygen complexes increases and the number of available active sites decreases. Previous investigations have reported that those groups affect the interaction of gaseous species with the carbon surfaces. ${ }^{23,33}$ To determine the effect of the existence of surface 


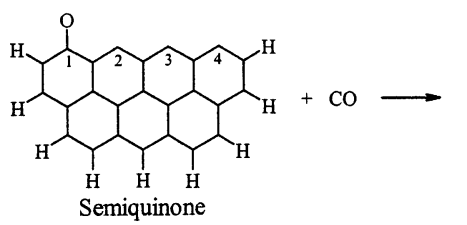

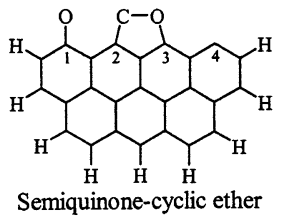

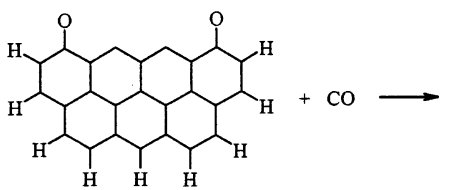

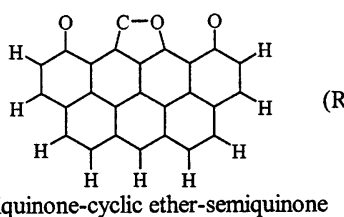

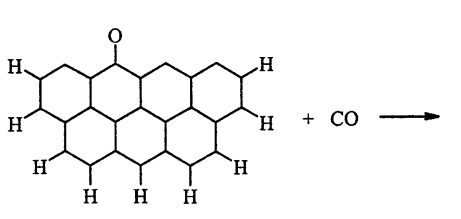

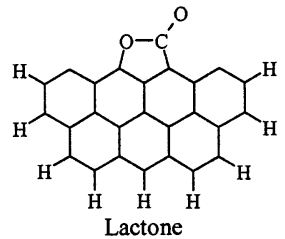

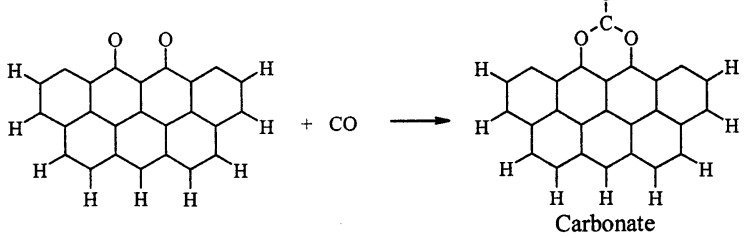

Figure 6. Reactions between $\mathrm{CO}$ and a surfaces with different degrees of oxidation.

TABLE 1: Effect of Oxygen Surface Complexes on the CO Interaction Energy and $\mathrm{CO}_{2}$ Desorption Energies (kcal/mol)

\begin{tabular}{lcc}
\hline \multicolumn{1}{c}{ complexes } & $\begin{array}{c}\mathrm{CO} \text { interaction } \\
\text { energy }\end{array}$ & $\begin{array}{c}\mathrm{CO}_{2} \text { desorption } \\
\text { energy }\end{array}$ \\
\hline semiquinone-cyclic ether (R1) & -43.4 & \\
semiquinone-cyclic ether- & -41.8 & \\
$\quad$ semiquinone (R2) & & \\
lactone (R3) & -63.9 & 91.5 \\
carbonate (R4) & -34.3 & 33.7
\end{tabular}

oxygen complexes on the $\mathrm{CO}$ adsorption on a carbonaceous surface, we studied four different model reactions as shown in Figure 6. In these models we used the semiquinone group to simulate the surface coverage of the carbonaceous surface since it is well-known both theoretically and experimentally that the semiquinone group is the most stable surface oxygen species on carbonaceous materials, and thus it is more likely to be present. ${ }^{7,36}$ Reactions R1 and R2 show the effects of the presence of one and two semiquinone groups on the adsorption of $\mathrm{CO}$ to form a five-member ring ether species. Reaction R3 shows the effect of one semiquinone group on $\mathrm{CO}$ adsorption that yields a lactone group. Reaction R4 shows the effects of high coverage where $\mathrm{CO}$ adsorbs on the second layer, i.e., on two adjacent semiquinone groups to form a carbonate species. Furthermore, we also examined possible $\mathrm{CO}_{2}$ desorption from these surface species, particularly from the lactone, and carbonate structures (Figure 6). All optimized structures have planar geometries. Calculated interaction energies for these processes are listed in Table 1.

We found that the presence of a semiquinone group on the carbonaceous model decreases the interaction energies by more than $10 \mathrm{kcal} / \mathrm{mol}$ (less exothermic) in the formation of either the cyclic ether or carbonyl groups on a zigzag model. The presence of the second semiquinone group follows the same trend. However, the change in the interaction energy is much less. CO interaction energy on an active site next to a semiquinone group that yields a lactone group (see Figure 6
TABLE 2: Mulliken Total Atomic Charges for Selected Carbons in Different Models

\begin{tabular}{clr}
\hline model & atom & charge \\
\hline carbonaceous (clean) & C1 & -0.0515 \\
& C2 & -0.1291 \\
& C3 & -0.1291 \\
carbonaceous oxidized with & C4 & -0.0515 \\
semiquinone group & C1 & 0.4052 \\
& C3 & -0.0822 \\
carbonaceous with semiquinone & C4 & -0.1096 \\
and cyclic ether groups & C2 & 0.0361 \\
& C3 & 0.0666 \\
& C4 & 0.1767 \\
& &
\end{tabular}

R3) is almost $-64 \mathrm{kcal} / \mathrm{mol}$, this value is less exothermic than the interaction energy reported by Montoya et al. ${ }^{23}$ who found a value of $-85 \mathrm{kcal} / \mathrm{mol}$ to obtain the same lactone group but after the interaction of $\mathrm{CO}_{2}$ with a clean carbonaceous surface. This is the most exothermic interaction energy we found in this study and it is due to the high stability of the lactone group; it is easy to see that $\mathrm{CO}$ desorption from a lactone group is a thermodynamically easier process than $\mathrm{CO}_{2}$ desorption. Therefore, the lactone complex does not play an important role in $\mathrm{CO}_{2}$ desorption produced after $\mathrm{CO}$ interaction, which is in agreement with experimental results obtained by TPD where it is reported that the main product from the oxygen surface complexes desorption is $\mathrm{CO}$. We also studied the possibility of $\mathrm{CO}$ interaction on an active site next to a semiquinone group that produces a peroxide group. We were not able to find a stable species of such a configuration.

To explain why the preadsorbed oxygen species decrease the $\mathrm{CO}$ interaction energies (see Figure 1 and Table 1), we evaluated the steric effect that a semiquinone group has over $\mathrm{CO}$ adsorption. To do this, we optimized a model with two semiquinone groups on which $\mathrm{CO}$ interacts to yield an ether group between them as shown in Figure 6 (R2). We found the $\mathrm{CO}$ adsorption energy for this process is only $1.6 \mathrm{kcal}$ less exothermic than that in the presence of just one semiquinone group (see Table 1). This indicates that steric effects play a minor role in the overall surface coverage effects of $\mathrm{CO}$ adsorption. We have also performed Mulliken population analysis (MPA). Mulliken total atomic charges for active sites in the seven six-member rings carbonaceous model (clean), oxidized model with a semiquinone group (Figure 6, the reactant of the $\mathrm{R} 1$ reaction), and model with semiquinone and ether groups (Figure 6, the product of the $\mathrm{R} 1$ reaction). The data are listed in Table 2. Since the carbon atom of the gas-phase CO molecule has a positive charge $(0.1744)$, the adsorption of $\mathrm{CO}$ is an electrophillic addition process. It can be seen that the oxygen of the semiquinone group withdraws electrons from the neighbor active carbon centers making them less electronegative and thus decreases the propensity for such an electrophillic addition. Therefore, the decreasing in the $\mathrm{CO}$ interaction energy in the presence of other surface oxygen species is due mostly to the electronic effects rather than steric effects.

$\mathrm{CO}_{2}$ Desorption. Desorption of $\mathrm{CO}_{2}$ after adsorption of $\mathrm{CO}$ molecules can contribute to the inhibition effects of $\mathrm{CO}$ in the gasification process in two ways. In one, $\mathrm{CO}$ reduces the oxidized carbon surface by removing an oxygen atom from a surface oxygen species that would desorb as $\mathrm{CO}$ in the gasification process. In the other way, it deposits back a carbon atom on the graphene surface according to the disproportionation reaction $2 \mathrm{CO}=\mathrm{C}+\mathrm{CO}_{2}$. Desorption of $\mathrm{CO}_{2}$ from the lactone and carbonate groups, which are products of reactions $\mathrm{R} 3$ and 
a)
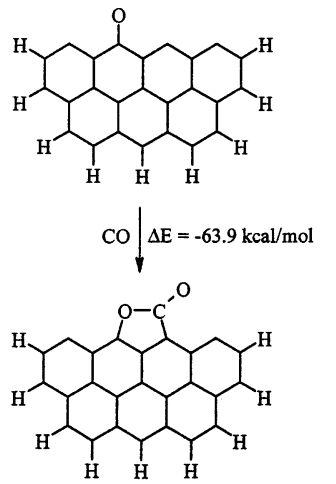

$\mathrm{CO} \Delta \mathrm{E}=-45.9 \mathrm{kcal} / \mathrm{mol}$

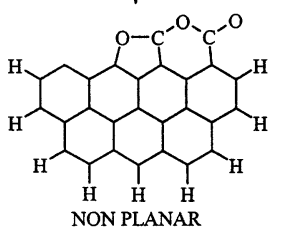

$\downarrow \Delta \mathrm{E}=82.4 \mathrm{kcal} / \mathrm{mol}$

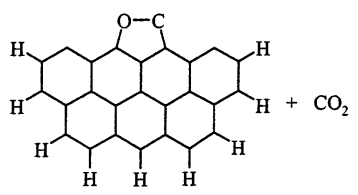

b)

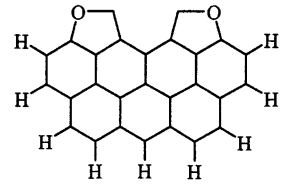

$\mathrm{CO} \downarrow \Delta \mathrm{E}=-85.5 \mathrm{kcal} / \mathrm{mol}$

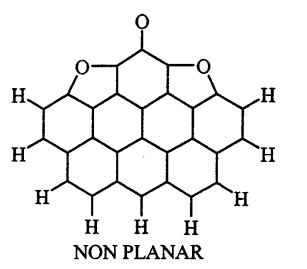

$\mathrm{CO} \downarrow \Delta \mathrm{E}=6.6 \mathrm{kcal} / \mathrm{mol}$

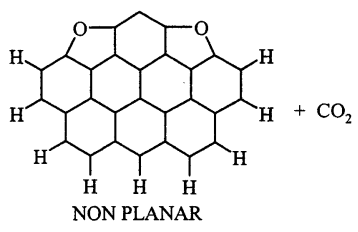

Figure 7. $\mathrm{CO}$ consecutive adsorption that favors (a) $\mathrm{CO}_{2}$ desorption and (b) six-member rings formation.

R4 respectively, illustrates the former effect. As discussed above, $\mathrm{CO}_{2}$ desorption from the stable lactone species is energetically less likely. Desorption of $\mathrm{CO}_{2}$ from a carbonate group requires an energy of $33.7 \mathrm{kcal} / \mathrm{mol}$, that is similar in magnitude to the adsorption of $\mathrm{CO}$ on two adjacent semiquinone groups $(-34.3$ $\mathrm{kcal} / \mathrm{mol})$. Thus, it is more likely that this is the preferred pathway for producing $\mathrm{CO}_{2}$ after $\mathrm{CO}$ interaction with an oxidized char, and can justify the fact that $\mathrm{CO}_{2}$ desorbs at lower rates (compared to $\mathrm{CO}$ desorption rates) during a TPD experiment after $\mathrm{CO}$ adsorption on carbonaceous materials. ${ }^{6,7,10}$

Figure 7 illustrates two different possible and energetically feasible $\mathrm{CO}_{2}$ desorption pathways after $\mathrm{CO}$ adsorption. One is the consecutive $\mathrm{CO}$ adsorption on available active sites next to a semiquinone group that yields a six-member heterocyclic ring as shown in Figure 7a. The resulted complex is nonplanar due to the presence of a five-member ring next to a six-member ring. The interaction energies for this process are $-63.9 \mathrm{kcal} /$ mol for the first $\mathrm{CO}$ adsorption and $-45.9 \mathrm{kcal} / \mathrm{mol}$ for the second one. This yields the total interaction energy of -109.8 $\mathrm{kcal} / \mathrm{mol}$. The $\mathrm{CO}_{2}$ desorption energy from this structure is 82.4 $\mathrm{kcal} / \mathrm{mol}$. Thus, desorption of $\mathrm{CO}_{2}$ after consecutive adsorption of $\mathrm{CO}$ is an exothermic process with the overall reaction energy of $-27.4 \mathrm{kcal} / \mathrm{mol}$. Another $\mathrm{CO}_{2}$ desorption pathway is also from a consecutive $\mathrm{CO}$ adsorption on a two nearby cyclic ether groups as shown in Figure 7b. Adsorption of the first $\mathrm{CO}$ yields an additional semiquinone group with the interaction energy of $-85.5 \mathrm{kcal} / \mathrm{mol}$. From the Hammond postulate, the barrier for such an adsorption if it exists should be very low. Adsorption of the second $\mathrm{CO}$ and subsequently desorbing $\mathrm{CO}_{2}$ require only $6.6 \mathrm{kcal} / \mathrm{mol}$. Thus, even if we start at the bicyclic ether group, desorption of $\mathrm{CO}_{2}$ from consecutive adsorption of two $\mathrm{CO}$ is still rather exothermic with the overall reaction energy of -78.9 $\mathrm{kcal} / \mathrm{mol}$.

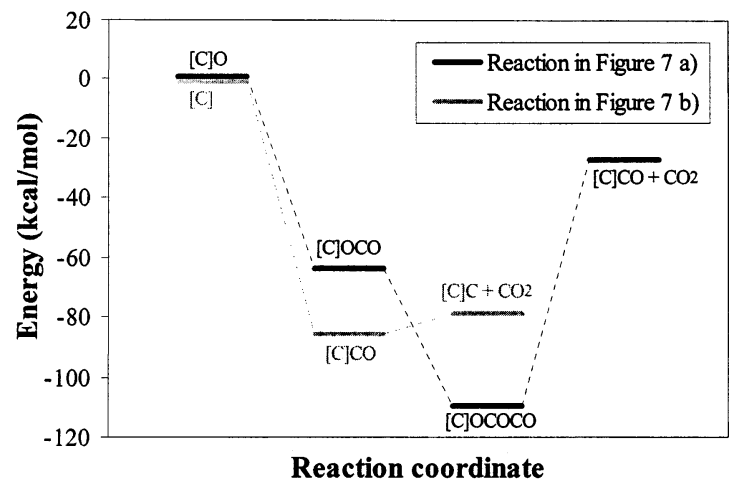

Figure 8. Schematic energy diagram for the energetic properties of reactions in Figure 7 (a) and 7 (b).

It is interesting to point out that the above results can also provide an insight into the mechanism for carbon single-wall nanotubes (SWNTs) production using $\mathrm{CO}$ as precursor via the disproportionation reaction of carbon monoxide,

$$
\mathrm{CO}+\mathrm{CO} \rightarrow \mathrm{C}(\mathrm{s})+\mathrm{CO}_{2}(\mathrm{~g})
$$

typical nanotube production temperatures are in the range 1000$1200{ }^{\circ} \mathrm{C}$. Here we assumed that CO-assisted SWNTs growth proceeds through the nanotubes open edge, as it has been assumed elsewhere, ${ }^{16}$ instead of a root growth. As discussed above, the two pathways (Figures 7a,b) lead to energetically favorable desorption of $\mathrm{CO}_{2}$ after consecutive adsorption of $\mathrm{CO}$ on an oxidized carbon surface. Thus, these pathways are possible routes for SWNTs growth, see Figure 8. As a cautious note, our models used here are somewhat oversimplified for studying SWNTs growth because of the use of planar graphene species as a model of carbon surface. To get a better understanding of the process it would be necessary to use nanotube models, to determine the transition states of the rate-limiting steps, and to show how the second, third, and other six-member rings could be formed. Currently work is under progress, and results will be published somewhere else.

\section{Conclusions}

It has been shown that $\mathrm{CO}$ adsorption on carbonaceous models is a thermodynamic favorable process due to its highly exothermic reactions. Therefore, we expect that the carbonized surface during combustion and gasification processes can adsorb $\mathrm{CO}$ and yield stable oxygen complexes such as ether, carbonyl, ketone, and semiquinone (on clean surfaces); lactone and carbonate (on oxidized surfaces). Ketone and lactone groups are highly stable, they would desorb $\mathrm{CO}$ at temperatures higher than $950{ }^{\circ} \mathrm{C}$. The presence of oxygenated groups, such as semiquinone, on a carbonaceous surface before $\mathrm{CO}$ adsorption makes the adsorption energy less exothermic, except for lactone formation. Oxygenated complexes formation due to $\mathrm{CO}$ interaction with carbonaceous surfaces can inhibit the gasification reaction due to the blockage of active sites.

We propose several pathways for $\mathrm{CO}_{2}$ desorption after consecutive $\mathrm{CO}$ adsorption on clean and oxidized surfaces, as has been observed experimentally. This reaction can either reduce the surface by removing a surface oxygen atom or leaving a carbon atom on the surface. Both effects lead to inhibition or retardation of the gasification reaction. The $\mathrm{CO}_{2}$ desorption through the $\mathrm{CO}$ disproportionation reaction also provides useful insight into the mechanism for SWNTs growth.

Acknowledgment. The authors thank Colciencias and the University of Antioquia for financial support of the project 1115- 
05-13663 and to the University of Antioquia for the financial support of the project IN383CE. This work is also supported in part by the University of Utah. J.F.E. acknowledges Colciencias and the University of Antioquia for the young researcher award. We also thank the Center for High Performance Computing at the University of Utah for computer support.

\section{References and Notes}

(1) Du, Z.; Sarofim, A. F.; Longwell, J. P.; Mims, C. A. Energy Fuels 1991, 5, 214-221.

(2) Tucker, B. G.; Mulcahy, M. F. R. Trans. Faraday Soc. 1969, 65, 274-286.

(3) Copestake, T. B.; Davidson, H. W.; Tonge, B. L. J. Appl. Chem. 1959, $9,74-84$ 134.

(4) Easler, T. E.; Bradt, R. C.; P. L. Walker, J. Carbon 1991, 29, 1125-

(5) Ranish, J. M.; P. L. Walker, J. Carbon 1986, 24, 109-114.

(6) Brown, T. C.; Haynes, B. S. Energy Fuels 1992, 6, 154-159.

(7) Marchon, B.; Tysoe, W. T.; Carrazza, J.; Heinemann, H.; Somorjai, G. A. J. Phys. Chem. 1988, 92, 5744-5749.

(8) Sibraa, A.; Newbury, T.; Haynes, B. S. Combust. Flame 2000, 120 $515-525$. 174.

(9) Marsh, H. Special Publication - Chemical Society 1978, 32, 133-

(10) Calo, J. M.; Hall, P. J. Applications of energetic distributions of oxygen surface complexes to carbon and char reactivity and characterization. In Fundamental Issues in Control of Carbon Gasification Reactivity; Lahaye, J., Ehrburger, P., Eds.; Kluwer Academic Publisher: The Netherlands, 1991; Vol. 192, pp 329-368.

(11) Beitel, G. A. J. Vac. Sci. Technol. 1972, 9, 370-372.

(12) Hall, P. J.; Calo, J. M. Energy Fuels 1989, 3, 370-376.

(13) Folman, M.; Fastow, M.; Kozirovski, Y. Langmuir 1997, 13, 1118 1122

(14) Fastow, M.; Kozirovski, Y.; Folman, M.; Heidberg, J. J. Phys.Chem. 1992, 96, 6126-6128.

(15) Gu, C.; Gao, G.-H.; Yu, Y.-X.; Nitta, T. Fluid Phase Equilib. 2002, 194-197, 297-307.

(16) Mann, D. J.; Halls, M. D.; Hase, W. L. J. Phys. Chem. B 2002 , $106,12418-12425$

(17) Wal, R. L. V.; Ticich, T. M.; Curtis, V. E. J. Phys. Chem. A 2000, 104, 7209-7217.

(18) Chiang, I. W.; Brinson, B. E.; Huang, A. Y.; Willis, P. A.; Bronikowski, M. J.; Margrave, J. L.; Smalley, R. E.; Hauge, R. H. J. Phys. Chem. B 2001, 105, 8297-8301.
(19) Zheng, B.; Lu, C.; Gu, G.; Makarovski, A.; Finkelstein, G.; Liu, J. Nano Lett. 2002, 2, 895-898.

(20) Nikolaev, P.; Bronikowski, M. J.; Bradley, R. K.; Rohmund, F.; Colbert, D. T.; Smith, K. A.; Smalley, R. E. Chem. Phys. Lett. 1999, 313 91-97.

(21) Bronikowski, M. J.; Willis, P. A.; Colbert, D. T.; Smith, K. A.; Smalley, R. E. J. Vac. Sci. Technol. 2001, 19, 1800-1805.

(22) Dai, H.; Rinzler, A. G.; Nikolaev, P.; Thess, A.; Colbert, D. T.; Smalley, R. E. Chem. Phys. Lett. 1996, 260, 471-475. 39.

(23) Montoya, A.; Mondragón, F.; Truong, T. N. Carbon 2003, 41, 29-

(24) Montoya, A.; Truong, T.-T. T.; Mondragón, F.; Truong, T. N. J. Phys. Chem. A 2001, 105, 6757-6764.

(25) Montoya, A.; Truong, T. N.; Sarofim, A. F. J. Phys. Chem. A 2000, $104,8410-8418$

(26) Montoya, A.; Truong, T. N.; Sarofim, A. F. J. Phys. Chem. A 2000, $104,6108-6110$

(27) Montoya, A. Development of a fundamental mechanism model for carbon gasification processes. Ph.D. Thesis, University of Antioquia, 2002

(28) Montoya, A.; Mondragón, F.; Truong, T. N. Fuel Process. Technol. 2002, 77-78, 125-130.

(29) Montoya, A.; Mondragón, F.; Truong, T. N. Fuel Process. Technol. 2002, 77-78, 453-458.

(30) Perry, S. T.; Hambly, E. M.; Fletcher, T. H.; Solum, M. S.; Pugmire, R. J. Proc. Combust. Inst. 2000, 28, 2313-2319.

(31) Chen, N.; Yang, R. T. Carbon 1998, 36, 1061-1070.

(32) Zhu, Z. H.; Finnerty, J.; Lu, G. Q.; Wilson, M. A.; Yang, R. T. Energy Fuels 2002, 16, 847-854.

(33) Zhu, Z. H.; Finnerty, J.; Lu, G. Q.; Yang, R. T. J. Phys. Chem. B 2001, 105, 821-830.

(34) Kyotani, T.; Tomita, A. J. Phys. Chem. B 1999, 103, 3434-3441.

(35) Frisch, M. J.; Trucks, G. W.; Schlegel, H. B.; Scuseria, G. E.; Robb, M. A.; Cheeseman, J. R.; Zakrzewski, V. G.; J. A. Montgomery, J.; Stratmann, R. E.; Burant, J. C.; Dapprich, S.; Millam, J. M.; Daniels, A. D.; Kudin, K. N.; Strain, M. C.; Farkas, O.; Tomasi, J.; Barone, V.; Cossi, M.; Cammi, R.; Mennucci, B.; Pomelli, C.; Adamo, C.; Clifford, S Ochterski, J.; Petersson, G. A.; Ayala, P. Y.; Cui, Q.; Morokuma, K.; Malick, D. K.; Rabuck, A. D.; Raghavachari, K.; Foresman, J. B.; Cioslowski, J.; Ortiz, J. V.; Baboul, A. G.; Stefanov, B. B.; Liu, G.; Liashenko, A.; Piskorz, P.; Komaromi, I.; Gomperts, R.; Martin, R. L.; Fox, D. J.; Keith, T.; AlLaham, M. A.; Peng, C. Y.; Nanayakkara, A.; Gonzalez, C.; Challacombe, M.; Gill, P. M. W.; Johnson, B.; Chen, W.; Wong, M. W.; Andres, J. L.; Gonzalez, C.; Head-Gordon, M.; Replogle, E. S.; Pople., J. A. Gaussian 98, Revision A.8; Gaussian, Inc.: Pittsburgh, PA, 1998.

(36) Montoya, A.; Mondragón, F.; Truong, T. N. J. Phys. Chem. A 2002, $106,4236-4239$ 